\title{
IMPACTOS DA PANDEMIA DA COVID-19 E ESTRATÉGIAS PARA A INCLUSÃO PRODUTIVA DE AGRICULTORES FAMILIARES NO TOCANTINS: ESTUDO DE CASO NA COOPRATO*
}

\author{
IMPACTS OF THE COVID-19 PANDEMIC AND STRATEGIES FOR THE PRODUCTIVE \\ INCLUSION OF FAMILY FARMERS IN TOCANTINS: A CASE STUDY IN COOPRATO
}

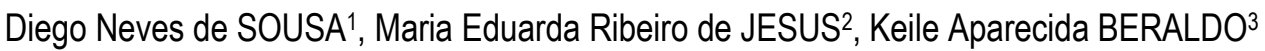

Artigo recebido em 13/11/2020, aceito em 18/03/2021, publicado em 18/04/2021.

Palavras-chave: Agricultura familiar; Experiências inovadoras; Politicas públicas; Desenvolvimento rural; Coronavírus

\section{Keywords:}

Family farming; Innovative experiences; Public policies; Rural development; Coronavirus

\section{RESUMO}

Os agricultores familiares e seus empreendimentos coletivos são importantes atores para manter o adequado abastecimento alimentar à população. Diante disso, o objetivo deste trabalho foi analisar os impactos da pandemia da Covid-19 para a inclusão produtiva de agricultores familiares no Tocantins por meio de um estudo de caso na Cooperativa Agroindustrial do Reassentamento Córrego Prata (Cooprato). Nos procedimentos metodológicos utilizou-se de uma revisão bibliométrica para mapear os estudos sobre experiências inovadoras na agricultura familiar e também de entrevista semiestruturada que foi realizada com a presidente da Cooprato. Os resultados apontam que as vendas da agricultura familiar caíram pela metade devido ao coronavírus e, em decorrência disso, os agricultores estão buscando mercados alternativos para superar as dificuldades de comercialização impostas pela pandemia.

\section{ABSTRACT}

Family farmers and their collective enterprises are important players in maintaining an adequate food supply with the population. Therefore, the objective of this work was to analyze the impacts of the Covid-19 pandemic for the productive inclusion of family farmers in Tocantins through a case study at the Córrego Prata Resettlement Agroindustrial Cooperative (Cooprato). In the methodological procedures, a bibliometric review was used to map studies on innovative experiences in family farming and also a semi-structured interview that was conducted with the president of Cooprato. The results obtained show that family farming sales fell by half due to the coronavirus and as a result, farmers are looking for alternative markets to overcome the marketing difficulties imposed by the pandemic.

\footnotetext{
* Este trabalho foi financiado pelo edital do Cnpq/Sescoop nº 07/2018.

1 Doutor em Desenvolvimento Rural (UFRGS). Analista da Embrapa Pesca e Aquicultura. E-mail: diegocoop@hotmail.com.

2 Graduanda do Curso de Ciências Econômicas pela Universidade Federal do Tocantins. E-mail: eduardaribeiro@mail.uft.edu.br.

${ }^{3}$ Doutora em Desenvolvimento Rural (UFRGS). Professora Adjunta da Fundação Universidade Federal do Tocantins - Campus de Palmas. E-mail: keile@uft.edu.br.
} 


\section{INTRODUÇÃO}

A crise mundial decorrente do surto pandêmico da Covid-19 não tem precedente e influência o funcionamento de praticamente todos os setores da economia. Embora se tenham direcionado inúmeros esforços no intuito de entender e minimizar os impactos causados pela supracitada pandemia, por ora prevalecem mais incógnitas do que respostas aos inúmeros problemas decorrentes desta. No Brasil e no Tocantins não é diferente.

O estado mais novo da Federação também sente de perto as repercussões negativas pelos efeitos da pandemia causada pelo vírus Sars-Cov-2, agente da Covid-19. Desde a separação do norte de Goiás em 1988, o Tocantins luta para combater a pobreza e as desigualdades sociais de sua população, o que acentuou no atual cenário de pandemia.

Mas, na situação vigente, os esforços do estado ficam cada vez mais incipientes o que afeta sobremaneira os públicos em situação de vulnerabilidade social, que no meio rural tocantinense atinge eminentemente os indígenas e os quilombolas (Sousa, 2020).

Influenciada pela lógica desenvolvimentista herdada de Goiás, a economia tocantinense tem como expoente as cadeias produtivas da pecuária e de grãos (Feitosa, 2011). No entanto, o escoamento das demais cadeias produtivas consideradas mais frágeis é influenciado pelas condições deficientes de acessibilidade. Prova disso é que não existe no Tocantins uma central de abastecimento de hortifrutigranjeiros de referência.

0 provimento da sociedade, sobretudo, voltado à aquisição de alimentos básicos, com vistas às recomendações de distanciamento social, bem como a intensificação das práticas de higienização passam a fazer parte das orientações advindas das agências de saúde e do poder público no intuito de minimizar a proliferação do vírus. Com isso, o sistema agroalimentar precisa se reinventar e desenvolver alternativas viáveis para se manter em meio à crise.

Neste sentido, os agricultores familiares e seus empreendimentos coletivos tornam-se importantes atores para manter 0 adequado abastecimento alimentar junto à população, principalmente, ao considerar que o estado do Tocantins é rico em recursos naturais com destaque para diversas espécies frutíferas do cerrado que são consumidas em maior escala, como a mangaba, pequi, babaçu, buriti, araticum, jatobá, baru, bacupari, dentre outros. Esses frutos são comercializados in natura nas principais feiras dos municípios tocantinenses pelos próprios agricultores (Pereira \& Santos, 2015).

Não obstante, após a confirmação do primeiro caso do novo coronavírus na capital do estado, Palmas, no dia 18 de março de 2020, diversas restrições foram recomendadas pelo poder público para combater o coronavírus e aumentar os cuidados com a população. Uma delas foi o fechamento das feiras livres no intuito de evitar aglomeração de pessoas. 
A feira livre é um tradicional mercado que ocupa espaços públicos em diversos municípios tocantinenses. Este é um ambiente propício para as trocas comerciais dos agricultores familiares e que também permite sua inclusão em demais mercados alternativos. Por isso, a relevância em manter e fomentar as feiras locais que contribuem significativamente para dinamizar as cadeias curtas de comercialização. № mês seguinte ao fechamento das feiras, após os atores reivindicarem a continuidade das costumeiras feiras, foi liberado seu funcionamento com a adoção de medidas protetivas aos agricultores e consumidores.

Com a reabertura, as associações de representantes dos feirantes buscaram se adaptar à nova realidade. Concomitantemente, iniciaram a utilizar de Tecnologias da Informação e Comunicação como forma de ampliar o acesso à internet e sua utilização pelos agricultores. Talvez de forma "forçada", os agricultores estão cada vez mais se inteirando no mundo tecnológico para não se distanciar do mercado.

Assim, a internet, principalmente por meio de seus canais de compras e de aplicativos de vendas, tem sido aliada dos agricultores comerciantes que tentam manter a comercialização de sua produção agrícola frente à baixa atividade nas feiras e, até mesmo, nas políticas alimentares de compras institucionais realizadas pelo poder público. Este cenário exige dos agricultores familiares uma resposta à crise, como é o caso de alguns que estão sendo capacitados (e também desafiados) para se adaptarem aos serviços online buscando, assim, se inserir nesta nova dinâmica de mercado. Por outro lado, os consumidores também estão em processo de adesão a esta modalidade de comercialização para evitar a saída de casa.

É preciso que além do aperfeiçoamento das entregas de delivery, os agricultores atentem-se aos cuidados de acondicionamento dos alimentos para que este modelo de negócio ganhe credibilidade e tenha real possibilidade de prosperar no mercado, além do já tradicional canal de comercialização que utilizam, neste caso as feiras livres. Dessa forma, esta situação possibilita vislumbrar uma oportunidade de negócio a posteriori.

Neste intento, os agricultores feirantes de Palmas estão em processo de organização para se inserirem devidamente no sistema delivery de produtos artesanais. Isto é relevante para o fomento da produção artesanal e agroecológica numa proposta de preservar costumes, hábitos e conhecimentos tradicionais dos diferentes grupos de agricultores familiares. Mesmo sendo um mercado consolidado em busca de adequações para continuar a atender os consumidores, também é importante a busca de alternativas para evitar que as feiras permaneçam parcialmente fechadas.

É consensualmente aceito que a destinação dos recursos por parte do Estado deve ser, neste momento, primordialmente para a saúde. Contudo, o poder público não deve deixar de promover estímulos aos empreendimentos da agricultura familiar que sobrevivem do comércio local e que, por sua vez, contribuem para a dinamização da economia do município de origem. Isto é crucial para que os efeitos negativos da situação pandêmica na produção agrícola e agropecuária sejam minimizados frente à 
possibilidade de instabilidade na disponibilização de alimentos e também em repercussão direta na segurança alimentar da população em situação de vulnerabilidade.

Neste sentido, o objetivo deste trabalho foi analisar os impactos da pandemia de Covid-19 e as estratégias de inclusão produtiva para agricultores familiares no Tocantins através de estudo de caso na Cooperativa Agroindustrial do Reassentamento Córrego Prata (Cooprato).

\section{MATERIAIS E MÉTODO}

Partindo do princípio de que qualquer caso que se estude em profundidade pode ser considerado representativo de muitos outros ou até de casos semelhantes, segundo Lakatos e Marconi (2003), o estudo de caso consiste na análise de determinados indivíduos, instituições, grupos ou comunidades, com a finalidade de obter generalizações e investigar um determinado tema ou problemática.

Nos procedimentos metodológicos utilizou-se de uma revisão bibliométrica para mapear os estudos sobre experiências inovadoras na agricultura familiar e também de entrevista semiestruturada realizada com a presidente da Cooprato. Esta cooperativa foi selecionada pela pesquisa, pois é uma organização coletiva considerada de referência em termos de inclusão produtiva de agricultores no estado do Tocantins (Sousa, 2019).

A técnica utilizada para analisar o objeto empírico deste estudo de caso foi a entrevista semiestruturada, realizada em julho de 2020, na sede da Cooprato. Contendo aproximadamente 20 perguntas, o roteiro foi estruturado em três partes e teve como intuito conhecer com afinco a experiência inovadora desta cooperativa, entender a estrutura organizacional da mesma, o que é produzido e qual 0 destino da produção; e os impactos que a pandemia tem causado à Cooprato e seus membros filiados.

Complementarmente a esta pesquisa de campo, utilizou-se de um estudo bibliométrico com 3 strings: agricultura familiar, experiências, inovação e tecnologias, na plataforma Google escolar, realizado no dia 02 de setembro de 2020. A partir dos strings utilizados foram selecionados 17 trabalhos científicos que abordavam algum tipo de experiência que tem contribuído para o desenvolvimento da agricultura familiar no Brasil. Neste contexto, as temáticas mais recorrentes encontradas foram: agroecologia e sustentabilidade; inclusão produtiva; inovação social; estratégias produtivas e comerciais; e transferência de tecnologia.

Desse modo, os trabalhos foram divididos e examinados por meio das 5 categorias analíticas identificadas. Assim, na próxima seção, serão apresentados e discutidos os estudos mapeados sobre experiências inovadoras da agricultura familiar a fim de fornecer subsídios ao desenvolvimento da atividade diante do contexto desafiador trazido pela pandemia da covid-19, bem como os resultados obtidos da pesquisa de campo na Cooprato. 


\section{RESULTADOS E DISCUSSÃO}

\subsection{Aspectos e apontamentos sobre as experiências inovadoras na agricultura familiar}

Ao mapear os trabalhos sobre experiências inovadoras na agricultura familiar em âmbito nacional foi possível identificar que mesmo em diferentes regiões do país, os casos de sucesso estão associados a uma série de temas relevantes e distintos que tem contribuído para o desenvolvimento da agricultura familiar no Brasil e dentre as temáticas mais recorrentes estão: agroecologia e sustentabilidade; inclusão produtiva; inovação social; estratégias produtivas e comerciais; e transferência de tecnologia, conforme pode ser observado no Quadro 1.

Quadro 1 - Temáticas identificas na revisão bibliográfica.

\begin{tabular}{|c|c|}
\hline Variável Analítica & Artigos \\
\hline \multirow[t]{3}{*}{$\begin{array}{l}\text { Agroecologia e } \\
\text { Sustentabilidade }\end{array}$} & $\begin{array}{l}\text { Extensão rural, agroecologia e inovação na agricultura familiar do Vale do } \\
\text { Jequitinhonha. }\end{array}$ \\
\hline & $\begin{array}{l}\text { Novidades (Novelty) na Agricultura Familiar e sua associação com a agroecologia } \\
\text { na produção de hortifrutigranjeiros no Território Sertão do Apodi (RN). }\end{array}$ \\
\hline & $\begin{array}{l}\text { Novo programa, novos atores: inovação e agroecologia na agricultura familiar do } \\
\text { Tocantins. }\end{array}$ \\
\hline \multirow[t]{4}{*}{ Inclusão produtiva } & $\begin{array}{l}\text { Inovação social e tecnologias sociais sustentáveis em relacionamentos } \\
\text { intercooperativos: um estudo exploratório no CREDITAG-RO. }\end{array}$ \\
\hline & $\begin{array}{l}\text { Inovações técnicas e suas relações com inovações sociais e institucionais no Norte } \\
\text { de Minas: experiências com agricultores familiares em Rio Pardo de Minas, MG. }\end{array}$ \\
\hline & Inovação e inclusão produtiva na agricultura familiar do Tocantins. \\
\hline & $\begin{array}{l}\text { Inovação social e tecnologia social: o caso da Cadeia Curta de agricultores } \\
\text { familiares e a alimentação escolar em Porto Alegre/RS. }\end{array}$ \\
\hline \multirow[t]{2}{*}{ Inovação social } & $\begin{array}{l}\text { Aprendizagem coletiva e construção social do saber local: o caso da inovação na } \\
\text { agricultura familiar da Paraíba. }\end{array}$ \\
\hline & $\begin{array}{l}\text { Os desafios da inclusão produtiva: o caso do programa nacional de inovação e } \\
\text { sustentabilidade na agricultura familiar no Tocantins. }\end{array}$ \\
\hline \multirow[t]{6}{*}{$\begin{array}{c}\text { Estratégias } \\
\text { produtivas e } \\
\text { comerciais }\end{array}$} & $\begin{array}{l}\text { Agricultura Familiar e Economia Solidária: a experiência da Associação MUTIRÃO, } \\
\text { na região do Baixo Tocantins, Amazônia Paraense. }\end{array}$ \\
\hline & Valorização de Produtos da Agricultura Familiar através do Design. \\
\hline & $\begin{array}{l}\text { As trajetórias de Serra do Mel e do Projeto Baixo-Açu/RN: experiências de } \\
\text { desenvolvimento com agricultura familiar. }\end{array}$ \\
\hline & $\begin{array}{l}\text { Estratégias de comercialização do pescado da agricultura familiar para a } \\
\text { alimentação escolar: a experiência no estado do Tocantins. }\end{array}$ \\
\hline & $\begin{array}{l}\text { Verticalização agroindustrial e gestão cooperativista: em busca de subsídios para } \\
\text { estratégias produtivas e comerciais na agricultura familiar. }\end{array}$ \\
\hline & $\begin{array}{l}\text { Agricultura familiar e desenvolvimento rural: um olhar sobre a experiência do } \\
\text { assentamento Coqueirinho - Palmas, TO. }\end{array}$ \\
\hline \multirow[t]{2}{*}{$\begin{array}{l}\text { Transferência de } \\
\text { tecnologia }\end{array}$} & $\begin{array}{l}\text { Transferência de tecnologias apropriadas para a agricultura familiar: uma } \\
\text { experiência de ação integrada no Estado de São Paulo. }\end{array}$ \\
\hline & $\begin{array}{l}\text { Transferência de tecnologia, agricultura familiar e desenvolvimento local - a } \\
\text { experiência do Projeto Silvânia. }\end{array}$ \\
\hline
\end{tabular}

Fonte: Os autores (2020). 
Três trabalhos tiveram como tema central a agroecologia e sustentabilidade no debate sobre novidades na agricultura familiar. O artigo de Noronha, Ribeiro e Augusto (2009) analisou o efeito da experiência de agricultores que praticam e divulgam os sistemas agroflorestais na região do Alto Jequitinhonha/MG e como essa prática influencia a população rural e as suas organizações coletivas que atuam no meio rural. Nunes et al. (2018) buscaram destacar as práticas e manejos na produção de hortifrutigranjeiros em experiências que associam a agricultura familiar com as práticas agroecológicas. Sousa, Charão-Marques e Kato (2017) buscaram compreender como a agroecologia e o debate sobre inovação para agricultura familiar emergiu no estado do Tocantins.

Em todos estes trabalhos foram identificado que os produtores da agricultura familiar se apresentam como atores participativos e protagonistas do desenvolvimento rural ao buscarem práticas que se autorreconhecem (Noronha et al., 2009; Sousa et al., 2017; Nunes et al., 2018). Segundo Sousa et al. (2017), o protagonismo dos agricultores ultrapassa a noção de que são apenas receptores passivos de tecnologias e de políticas públicas, apontando que, ao serem considerados atores sociais significantes de determinado processo sociotécnico como, por exemplo, ao fortalecer e promover práticas agroecológicas, podem ser atores partícipes na definição de estratégias e na busca por soluções de problemas do campo em conjunto com técnicos e pesquisadores.

Para Nunes et al. (2018), o desafio para os agricultores são fortalecer e promover a construção do conhecimento agroecológico e, neste sentido, a construção de programas e acesso às políticas públicas que visem à geração de inovação tecnológica na agricultura familiar a partir da conservação do meio ambiente e de práticas de produção sustentáveis. Apesar das tradicionais limitações, os agricultores familiares têm potencial significativo para promover a transição de uma agricultura moderna e produtiva para sistemas agroecológicos (Nunes et al., 2018).

As questões atinentes à inclusão produtiva e a inovação social foram identificadas em seis trabalhos publicados. O artigo de Oliveira e Silva (2012) teve como objetivo apresentar uma proposta de framework que permita observar a presença dos aspectos inovadores, tecnologias sociais e empreendedorismo coletivo em relacionamentos intercooperativos no Sistema de Cooperativas de Crédito Rural da Agricultura Familiar e Economia Solidária (Creditag), no estado de Rondônia.

Os resultados apontaram que o modelo de gestão cooperativo busca promover a satisfação das necessidades humanas, integração coletiva, preservação ambiental, simultaneamente com 0 desenvolvimento econômico e social, geração de emprego e renda. Observa-se, também, uma motivação maior para o empreendedorismo coletivo, no qual o princípio da intercooperação está promovendo nos cooperados estímulos e iniciativas de ordem coletiva para melhoria da qualidade de vida, ao gerar mais oportunidades, despertando para novas habilidades e novos conhecimentos. 
O trabalho de Correia e Lima (2015) buscou apresentar alguns aspectos da relação entre inovações técnicas, sociais e institucionais em comunidades de agricultores familiares do Norte de Minas Gerais. Entre os resultados, identificou-se que as experiências relatadas demonstraram que as inovações tecnológicas criadas pelas comunidades de agricultores familiares foram produtos de inovações sociais e institucionais e que de todo modo não é possível analisar a inovação de forma segmentada, ou seja, inovação técnica separada das inovações sociais e institucionais.

Ao mesmo tempo, em que a estrutura organizacional da comunidade é valorizada, fortalecida e até aprimorada, os desafios criados pelo surgimento de novas formas de relação entre as pessoas são mais facilmente enfrentados, podendo dar origem a inovações tecnológicas muito bem aplicadas à solução dos problemas ligados à produção agrícola.

Franzoni (2015) analisou uma cadeia agroalimentar curta, formada por associações e cooperativas de agricultores familiares fornecedoras da alimentação escolar em Porto Alegre/RS sob as perspectivas da inovação, tecnologia social e cadeias curtas agroalimentares. Os resultados evidenciaram que todas as dimensões de inovação social estavam presentes na cadeia curta estudada e esses aspectos auxiliaram no processo de transferência de tecnologia social, assim como trouxeram benefícios para os atores envolvidos. As políticas públicas alimentares, principalmente a resolução do Programa Nacional de Alimentação Escolar (PNAE), em 2009, favoreceu a compra de produtos provenientes da agricultura familiar e de seus empreendimentos coletivos, e foram primordiais para a consecução desses resultados.

Sousa et al. (2018) analisaram a construção de um referencial sobre inclusão produtiva a partir das oficinas temáticas do Programa Nacional de Inovação e Sustentabilidade na Agricultura Familiar no estado do Tocantins e como foi possível problematizar e resgatar a discussão sobre a inovação e a inclusão produtiva no estado. Um dos primeiros elementos que se depreende da experiência é que havia um distanciamento entre os múltiplos atores ligados à agricultura familiar e, em especial, relacionados à produção de conhecimentos e inovação e com a aplicação da oficina os atores se aproximaram e articularam ações em conjunto numa proposta formalizada em uma agenda de ações para a agricultura familiar tocantinense. Os autores diagnosticaram, ainda, que os desafios ligados à inclusão produtiva de agricultores familiares estão diretamente relacionados à questão da dificuldade de acesso ao serviço de extensão rural, falta de inspeção sanitária, baixa participação em políticas públicas de comercialização e dificuldade de organização social e produtiva.

Para Sabourin (2013), é difícil propor inovações ou estabelecer referências técnicas sem se referir aos sistemas sociotécnicos locais de conhecimento mediante os quais tais inovações estão sendo constantemente avaliadas, adaptadas e adotadas. Nesse contexto, Correia e Lima (2015) e Sousa et al. (2018), entendem que a integração e o compartilhamento de expectativas, unidos ao fortalecimento dos 
saberes da comunidade local permitem que os desafios sejam enfrentados com maior facilidade, podendo dar origem as inovações tecnológicas e novidades no campo e, assim, corroborar com a formação de nichos de inovação e espaços de concertação com o intuito de promover a devida inclusão produtiva dos agricultores familiares.

A construção de estratégias produtivas e de comercialização também foi identificada como perspectiva de desenvolvimento e fortalecimento da agricultura familiar. O estudo de Cribb (2008) buscou identificar estes elementos. Ao analisar uma cooperativa no Norte Fluminense foi constatado que o modelo de verticalização agroindustrial de cooperativas é um mecanismo de gestão profissionalizada capaz de assessorar os agricultores familiares a aproveitarem eficientemente seus recursos. Ela é geralmente reconhecida como uma das mais promissoras estratégias de produção e comercialização na agricultura familiar, no entanto, é influenciada pelo ambiente institucional e organizacional.

O modelo de verticalização é uma estratégia de crescimento conforme a qual uma organização se envolve em mais de um estágio da cadeia de suprimento de um determinado setor produtivo. Geralmente uma cooperativa central se conecta com suas cooperativas singulares e cooperados (Sousa et al., 2014). Conhecida também sob o termo de integração vertical, ela se concretiza através de uma das duas seguintes formas: a verticalização para trás, quando a organização entra em estágios produtivos anteriores àquele já dominado por ela; e a verticalização para frente, quando a organização incorpora estágios produtivos posteriores àquele já dominado por ela (Cribb, 2008).

Em relação ao estudo de Pereira et al. (2004), verificou-se que a competitividade dos produtos da agricultura familiar estava influenciada em grande parte pelas embalagens/rótulos utilizados. Observou-se, também, que os próprios agricultores tinham consciência desta fragilidade, mas que em função do desconhecimento e/ou a falta de recursos se tornava inviável ter algum tipo de ação mercadológica com relação a esses aspectos.

Por sua vez, constatou-se que os agricultores tinham como referência apenas posicionar seus produtos no mercado em termos de manter a qualidade. O estudo foi desenvolvido na região de Mafra/SC e ofereceu aos pequenos produtores o apoio necessário para que seus negócios se desenvolvessem por meio da utilização do "Design" como instrumento de agregação de valor para seus produtos. Esta estratégia é utilizada em países europeus, como forma de valorizar regiões produtoras de produtos específicos e de forma estruturada.

Políticas públicas de apoio à comercialização de produtos oriundos da agricultura familiar corroboram a inclusão e fortalecimento da cadeia produtiva formada por agricultores. Sousa, Kato, Niederle, Freitas e Milagres (2019) analisaram a experiência das estratégias de comercialização do pescado da agricultura familiar para a alimentação escolar no estado do Tocantins, através do mercado institucional. Com efeito, as 
estratégias adotadas nesta realidade conseguiram de certa forma articular alternativas viáveis e factíveis para escoar a produção de pescado da agricultura familiar e podem servir como benchmarking para que outros produtos tenham alternativas de comercialização no contexto de políticas alimentares. Esta experiência se destacou porque conseguiu articular a produção de pescado proveniente da colônia de pescadores artesanais que não tinha estrutura de processamento com um frigorífico privado que passou a processar o pescado. 0 pagamento deste serviço para o frigorífico foi com parte de recursos obtidos com o acesso ao mercado institucional.

Nunes (2003) identificou e buscou compreender como cooperativas e comunidades, que foram submetidas a políticas públicas semelhantes num determinado período obtiveram trajetórias diferentes de experiências inovadoras na agricultura familiar. Os objetos de análise foram o município de Serra do Mel e o Projeto Baixo-Açu, ambos localizados no Rio Grande do Norte. O estudo constatou que as diferenças entre os caminhos trilhados estão relacionadas à combinação de elementos estruturais, institucionais e culturais. Dentre estes estão, a fragilidade institucional da maioria dos mecanismos e instrumentos de gestão; recursos financeiros limitados, a insuficiência e deficiência tecnológica da unidade produtiva dos agricultores.

Nessa mesma perspectiva, Miranda (2007) analisou o desmembramento de uma fazenda comprada pelo governo do estado do Tocantins doada para a instalação de um assentamento rural de ocupação agrária. Os resultados apontaram que as experiências vivenciadas coletivamente junto ao "Assentamento Coqueirinho" contribuíram para a valorização do saber de uma dada comunidade a respeito do ambiente em que vive.

Melhor qualidade de vida; geração de emprego e renda; acesso a bens fundamentais como saúde e educação; além da formação de assistência técnica na produção agrícola, foram temas essenciais elencados por Reis, Nascimento, Felizardo e Santos (2015) para que agricultores familiares na região do Baixo Tocantins/PA se organizassem para garantir melhorias às populações ribeirinhas, a partir das práticas econômicas e sociais pautadas pela Economia Solidária. Os efeitos obtidos demonstram que ao fomentar a organização de agricultores familiares, via empreendimento solidário, é possível realizar atividades de formação capazes de fortalecer o acesso a bens e serviços de uso coletivo.

Zoby et al. (2003) e Hanashiro et al. (2011) analisaram experiências inovadoras na agricultura familiar a partir da transferência de tecnologias. 0 primeiro trabalho abordou sobre as experiências de um projeto implantado pela Empresa Brasileira de Pesquisa Agropecuária (Embrapa), em 1987, na região de Silvânia/GO; o segundo trabalho tratou de uma experiência de ação integrada entre diversas instituições no estado de São Paulo visando à transferência de tecnologias apropriadas para o contexto da agricultura familiar. 
De acordo com Zoby et al. (2003), os resultados do Projeto Silvânia evidenciaram que a abordagem focada apenas na tecnologia não é o suficiente para o desenvolvimento da agricultura familiar. 0 componente organizacional é decisivo no próprio processo de transferência e de adoção de tecnologias. Os resultados obtidos por Hanashiro et al. (2011) identificaram essa mesma perspectiva, pois a transferência de tecnologia só se efetiva ao passo que o grupo esteja organizado, tenha adequada estrutura de gestão, e que insira 0 jovem agricultor nessa dinâmica como forma de promover ações de intergeracionalidade.

Portanto, verifica-se que as experiências identificadas contribuem para que técnicos e mediadores do meio rural possam ter referências inovadoras de inclusão produtiva para intervenções sociotécnicas e, assim, adaptar o seu processo de intervenção de acordo com a realidade local. Ao considerar que os agricultores familiares são atores sociais significantes para essas intervenções, estes podem ser atores partícipes no fortalecimento e promoção de práticas agroecológicas, na definição de estratégias e na busca por soluções de problemas do campo em conjunto com técnicos e pesquisadores. Assim, a integração e o compartilhamento de expectativas, unidos ao fortalecimento dos saberes da comunidade local permitem que os desafios sejam enfrentados com maior facilidade, podendo dar origem as novidades e inovações tecnológicas no campo.

Evidencia-se, assim, que apenas o processo de transferência de tecnologias não é o suficiente para o desenvolvimento da agricultura familiar e que o componente organizacional é decisivo para o seu processo de ascensão, o fortalecimento e a construção de discussões a cerca do empreendedorismo coletivo. Este é um processo de intervenção no qual foi identificado que o princípio da intercooperação promove para os cooperados estímulos e iniciativas de ordem coletiva para melhoria da qualidade de vida, para gerar mais oportunidades de renda e despertar para novas habilidades e novos conhecimentos.

\subsection{0 caso da Cooprato}

A Cooperativa Agroindustrial do Reassentamento Córrego Prata, conhecida popularmente como Cooprato, está localizada no município de Porto Nacional divisa com Palmas, capital do estado do Tocantins. Possui aproximadamente 50 associados que dependem da atividade da agricultura para a subsistência da família, destacando-se a maior presença de reassentados. Estes fazem parte de uma população atingida por barragem decorrente da implantação de hidrelétricas no estado.

Para Sousa (2019), a Cooprato tem como vantagem em relação aos demais empreendimentos coletivos da agricultura familiar o fato de estar localizada próxima à capital do estado, que tem grande demanda por gêneros alimentícios. Outro fator preponderante é que está situada no Projeto de irrigação São João, no qual possui infraestrutura de irrigação para cultivos de frutas e verduras. Com isso, os agricultores conseguem produzir no cerrado o ano todo, dada a abundância hídrica na localidade. 
Os principais meios para escoar a produção são através da venda nas feiras livres e nos mercados institucionais. Antes da pandemia, a cooperativa produzia cerca de quatro a cinco toneladas de alimentos/mês, mas diante do surto da Covid-19 a realidade tem sido outra. De acordo com a presidente da Cooprato, as vendas da associação caíram mais da metade, isso porque diversas restrições sanitárias foram recomendadas pelo poder público a fim de evitar a proliferação do vírus, sendo o fechamento das feiras uma delas.

Após a reinvindicação dos agricultores (e seus movimentos sociais) foi feita a reabertura gradual das feiras, porém com diminuição de público e, consequentemente, de clientes. Este não foi o único desafio a ser enfrentado pelos agricultores. Identificou-se neste estudo que dentro da própria cooperativa existem cooperados que estão no grupo de risco para o novo coronavírus e estes estão impossibilitados de ir à feira comercializar os seus produtos. Infere-se que os efeitos da pandemia têm atingido diretamente a vida e 0 cotidiano desses agricultores familiares que relatam não estar vendendo nem um terço da produção que era comercializada anteriormente a essa situação de pandemia.

Além das feiras tradicionais, o PNAE era o principal meio de comercialização da cooperativa. Cerca de $80 \%$ das vendas eram para o mercado institucional, pois a Cooprato abastecia as escolas dos municípios de Palmas e Porto Nacional. Como uma das principais formas de evitar aglomeração e a contaminação pela Covid-19 foi suspenso o calendário escolar. O fornecimento para esse mercado foi interrompido e consequentemente a fonte de renda desses agricultores também foi impactada.

Diante de uma possível retomada às atividades, os produtores da agricultura familiar terão que se adaptar a um "novo normal", isso porque os alimentos não poderão chegar ao destino final da mesma forma que antes. O que era fornecido em caixaria, por exemplo, deverá ser embalado e ainda mais higienizado. Em relato, a presidente da cooperativa afirmou que tem recebido orientações de medidas sanitárias e boas práticas por parte dos órgãos responsáveis sobre o manuseio e uma nova forma de distribuição de alimentos as quais os produtores terão que se adaptar. Isto porque a Cooprato foi contemplada com um projeto do Programa de Aquisição de Alimentos (PAA), o que minimizou o impacto causado pela diminuição da receita da cooperativa devido à pandemia.

Nesse contexto, além das mudanças estruturais na preparação do produto para a venda ao consumidor final, o principal gargalo no atual momento é conseguir diversificar os canais de comercialização, pois os dois principais mercados da Cooprato foram negativamente impactados. $O$ isolamento social ocasionou grande redução de demanda por seus produtos, o que tem causado prejuízo e perdas monetárias aos agricultores familiares, assim como tem ocorrido nos demais setores da economia. Antes mesmo de começar a vigorar os decretos e as restrições impostas pelo poder público, o impacto da pandemia já havia atingido a comercialização de produtos nas feiras livres, pois os principais consumidores de seus produtos, 
que costumam frequentar esse ambiente com maior assiduidade, era o grupo da terceira idade, que valoriza os produtos artesanais e agroecológicos. Por conta da Covid-19, os idosos foram orientados a não sair de casa e, na sua maioria, a compra dos produtos adquiridos nas feiras está sendo feita por terceiros e, provavelmente, em outros canais de comercialização.

Como alternativa para superar a dificuldade de comercialização imposta pela pandemia, os agricultores feirantes estão em busca de novos mercados. Há exemplo disso, os cooperados da Cooprato estão em processo de organização para se inserirem devidamente no sistema delivery de produtos artesanais através da produção e venda de cestas de alimentos para a população do município de Palmas. Diante da atual situação a qual se encontra a cooperativa, a busca por adequações para continuar a atender os consumidores se faz necessária, abrindo caminhos para a inclusão em mercados alternativos e para a dinamização das cadeias curtas de comercialização.

Além do interesse em acessar outros mercados, para não ficarem "reféns" de um único canal de comercialização, o estudo identificou que de antemão tivessem outras oportunidades como, por exemplo, através da ampliação dos mercados institucionais ou de feiras, a cooperativa teria a opção de comercializar outros produtos ou até aumentar a sua produção. Segundo a presidente da Cooprato, ainda falta mercado para os agricultores familiares cooperados, influenciado principalmente pela pandemia do coronavírus, visto que não estão inteiramente incluídos na atual dinâmica de comercialização, sendo que eles têm condições e potencialidade para produzir e prosperar em outros tipos de mercados, além dos que já participam. Para isso, esse grupo de agricultores precisa de assessoria especializada como forma de monitorar as mudanças que vêm ocorrendo nos mercados e ajustar suas ações de acordo com as demandas dos consumidores como, por exemplo, o aumento na venda de alimentos por aplicativos e entregas por delivery.

O governo do estado do Tocantins precisa formular políticas públicas específicas para a agricultura familiar, diante do cenário negativo provocado pela pandemia e dada a inexistência de política pública estadual expressiva para atender as reais necessidades da região e deste público (Sousa, 2019). A ideia é buscar a consolidação de setores ou atividades potenciais do meio rural tocantinense por meio da proposição de ações de inclusão produtiva para fortalecer as cadeias produtivas que possuem proximidade com a cultura alimentar regional. Políticas públicas de apoio à comercialização e ao fortalecimento das cadeias curtas de produtos oriundos da agricultura familiar que corroboram para a inclusão e desenvolvimento desse público, além de estratégias de valorização da produção por meio de programas de apoio para as certificações agroecológicas e demais ações como instrumento de agregação de valor para esses produtos.

No caso da Cooprato, esta cooperativa é referência da agricultura familiar no Tocantins por ter sido considerada no estudo de Sousa (2019) como a principal experiência inovadora de inclusão produtiva de agricultores familiares no estado. Para manter esta referência é importante que o grupo continue em 
cooperação, tenha apoio de parceiros, capacitação e que continue acessando políticas públicas específicas à realidade local. Isto contribui para que os agricultores busquem (re)construir formas alternativas de produção, abastecimento e comercialização de alimentos e como forma também da população local reconhecer e valorizar os produtos provenientes da agricultura familiar.

\section{CONCLUSÕES}

Os principais resultados obtidos deste estudo de caso evidenciaram que, devido ao surto de Covid19, as vendas da Cooprato reduziram em mais da metade, em comparação com o período anterior à pandemia, em decorrência do isolamento social e das medidas restritivas impostas pelo poder público. Antes da pandemia, a cooperativa produzia cerca de quatro a cinco toneladas de alimentos/mês e essa realidade têm sido outra, pois os principais meios de escoar a produção eram através da venda nas feiras livres e nos mercados institucionais, que foram severamente afetados pela pandemia.

Em um primeiro momento, as feiras do município de Palmas haviam sido totalmente fechadas, no entanto, após a reinvindicação dos agricultores familiares foi feita a reabertura gradual das feiras, mas mesmo com medidas protetivas houve diminuição de público e, consequentemente, de clientes.

Por um lado, foi constatado que dentro da própria cooperativa existem cooperados que estão no grupo de risco para o coronavírus e estão impossibilitados de comercializar os seus produtos nas feiras. Por outro, os idosos eram os principais consumidores da Cooprato. Com o isolamento social, este grupo de risco diminuiu consideravelmente as compras na feira e, concomitantemente, na Cooprato.

Outro motivo para a diminuição drástica da receita da cooperativa foi a suspensão do fornecimento de alimentos para as escolas da rede municipal de ensino de Palmas e Porto Nacional. Cerca de $80 \%$ das vendas eram para o PNAE e sem a previsão de retorno para as aulas os efeitos da pandemia têm atingido diretamente a vida, o cotidiano e, consequentemente, a fonte de renda desses agricultores.

Como alternativa para superar a dificuldade de comercialização imposta pela pandemia, os agricultores estão em busca de novos mercados para continuar a atender aos consumidores e escoar a produção que se encontra parada. Além do interesse em acessar outros mercados, para não ficarem "reféns" de um único canal de comercialização, o estudo identificou que de antemão tivessem outras oportunidades como, por exemplo, a ampliação dos mercados institucionais ou de feiras a construção de programas e acesso às políticas públicas que visem à geração de inovação tecnológica na agricultura familiar a partir da produção agroecológica e acesso á definição de estratégias inclusivas na busca por soluções de problemas do campo em conjunto com técnicos e pesquisadores, a cooperativa e os demais agricultores familiares teriam maiores oportunidades de acesso ao recebimento de tecnologias e o compartilhamento de saberes locais. 
Portanto, diante do cenário negativo provocado pela pandemia cabe a Cooprato (e demais empreendimentos coletivos da agricultura familiar) a busca por alternativas para a comercialização de seus produtos, como é o caso da nova tendência de delivery no setor de alimentação, e ao governo do Tocantins formular políticas públicas específicas para a agricultura familiar, dada a inexistência de política pública estadual expressiva para atender as reais necessidades da região e deste público. A ideia é buscar a consolidação de setores ou atividades potenciais do meio rural tocantinense por meio da proposição de ações de inclusão produtiva a fim de fortalecer as cadeias produtivas que possuem proximidade com a cultura alimentar regional.

\section{REFERÊNCIAS}

Correia, J. B \& Lima, H. C. (2015). Inovações técnicas e suas relações com inovações sociais e institucionais no Norte de Minas: experiências com agricultores familiares em Rio Pardo de Minas, MG. Sustentabilidade em Debate, Brasília, 6(1), p.138-154.

Cribb, A. Y. (2008). Verticalização agroindustrial e gestão cooperativista: em busca de subsídios para estratégias produtivas e comerciais na agricultura familiar. In: Congresso da Sociedade Brasileira de Economia, Administração e Sociologia Rural, 46, Rio de Janeiro.

Feitosa, C. O. (2011). Do antigo norte de Goiás ao estado do Tocantins: elementos de uma economia em formação. Tese (Doutorado em Desenvolvimento Econômico). Curso de Pós-graduação em Desenvolvimento Econômico, Universidade Estadual de Campinas, Campinas.

Franzoni, G. B. (2015). Inovação social e tecnologia social: 0 caso da Cadeia Curta de agricultores familiares e a alimentação escolar em Porto Alegre/RS. Dissertação (Mestrado em Administração) - Curso de Pós-graduação em Administração, Universidade Federal do Rio Grande do Sul, Porto Alegre.

Hanashiro, M. M; Matsuura, F. C. A. U; Lima, I. A; Beriam, L. O. S; Maddarena, E. F \& Minitti, A. F. (2011). Transferência de tecnologias apropriadas para a agricultura familiar: uma experiência de ação integrada no estado de São Paulo. Cadernos de Ciência \& Tecnologia, Brasília, 28(1), p. 51-80.

Lakatos, E. M \& Marconi, M. A. (2003). Fundamentos de metodologia científica. 5. ed. São Paulo: Atlas.

Miranda, J. C. (2007). Agricultura familiar e desenvolvimento rural: um olhar sobre a experiência do assentamento Coqueirinho - Palmas, TO. Dissertação
(Mestrado em Geografia) - Curso de Pós-graduação em Geografia. Departamento de Geociências. Universidade Federal de Mato Grosso do Sul, Aquidauna.

Noronha, A. F. B; Ribeiro, A. E. M \& Augusto, E. A. (2009). Extensão rural, agroecologia e inovação na agricultura familiar do vale do Jequitinhonha. Organizações Rurais \& Agroindustriais, 11(2), p. 233250.

Nunes, E. M. (2003). As trajetórias de Serra do Mel e do Projeto Baixo-Açu/RN: experiências de desenvolvimento com agricultura familiar. Dissertação (Mestrado em Desenvolvimento Econômico). Universidade Federal de Uberlândia, Uberlândia.

Nunes, E. M; França, A. R. M; Lima, J. S. S \& Medeiros, L. S. (2018). Novidades (Novelty) na Agricultura Familiar e sua associação com a agroecologia na produção de hortifrutigranjeiros no Território Sertão do Apodi/RN. Redes - Revista do Desenvolvimento Regional, 23(1), p.213-236.

Oliveira, N. D. A \& Silva, T. N. (2012). Inovação social e tecnologias sociais sustentáveis em relacionamentos intercooperativos: um estudo exploratório no CREDITAG-RO. Revista de Administração da UFSM, 5(2), p. 277-295.

Pereira, D; Merino, E; Pereira, L. K \&Altmann, R. (2004). Valorização de Produtos da Agricultura Familiar através do Design. Florianópolis: SAR/ Instituto Cepa/SC, Funcitec.

Pereira, A. C \& Santos, E. R. (2015). Frutas nativas do Tocantins com potencial de aproveitamento econômico. Agri-environmental Sciences, Palmas, 1(1), p.22-37.

Reis, A. A; Nascimento, W. L. N; Felizardo, A. O \& Santos, A. R. S. (2015). Agricultura Familiar e 
Economia Solidária: a experiência da Associação MUTIRÃO, na região do Baixo Tocantins, Amazônia Paraense. Revista Tecnologia e Sociedade, Curitiba, 11(22), p.120-142.

Sabourin, E. (2007). Aprendizagem coletiva e construção social do saber local: o caso da inovação na agricultura familiar da Paraíba. Revista Estudos Sociedade e Agricultura, v. 9, n. 1, p.37-61.

Sousa, D. N. (2019). Mediadores sociais e políticas públicas de inclusão produtiva da agricultura familiar no Tocantins: (des)conexões entre referenciais, ideias e práticas. Tese (Doutorado em Desenvolvimento Rural) - Curso de Pós-Graduação em Desenvolvimento Rural, Faculdade de Ciências Econômicas, Universidade Federal do Rio Grande do Sul, Porto Alegre.

Sousa, D. N. (2020). Quilombolas e indígenas: análise dos públicos da agricultura familiar excluídos das políticas públicas em uma região da amazônia legal. Humanidades \& Inovação, 7(16), p. 1-13.

Sousa, D. N; Charão-Marques, F \& Kato, H. C. A. (2017). Novo programa, novos atores: inovação e agroecologia na agricultura familiar do Tocantins. Extensão Rural, Santa Maria, 24(3), p. 44-62.

Sousa, D. N; Amodeo, N. B. P; Macedo, A. S; Milagres, C. S. F. (2014). A comunicação na articulação agroindustrial entre uma cooperativa central, suas cooperativas singulares e cooperados. Revista de Economia e Sociologia Rural, 52 (3), p. 495-514.

Sousa, D. N; Kato, E. C. A; Niederle, P. A; Freitas, A. A \& Milagres, C. S. F. (2019). Estratégias de comercialização do pescado da agricultura familiar para a alimentação escolar: a experiência no estado do Tocantins. Cadernos de Ciência \& Tecnologia, 36(2), e26450.

Sousa, D. N; Niederle, P. A; Charão- Marques, F \& Freitas, A. A. (2017). Os desafios da inclusão produtiva: o caso do programa nacional de inovação e sustentabilidade na agricultura familiar no Tocantins. In: Congresso da Sociedade Brasileira de Economia, Administração e Sociologia Rural, 55, Santa Maria.

Sousa, D. N; Niederle, P. A; Marques-Charão, F \& Freitas, A. A. (2018). Inovação e inclusão produtiva na agricultura familiar do Tocantins. Revista Grifos, 27(45), p. 204-224.

Zoby, J. L. F; Xavier, J. H. V \& Gastal, M. L. (2003). Transferência de tecnologia, agricultura familiar e desenvolvimento local: à experiência do Projeto Silvânia. Planaltina, DF: Embrapa Cerrados. 